\title{
Breves apontamentos acerca da Criminologia Crítica e o Sistema Penal Seletivo Vigente
}

\author{
Josiéli Denise Brum dos Santos $^{l}$; Athena de Albuquerque Farias ${ }^{2}$; Gisanne de Oliveira Marinho 3; \\ Larice de Sousa Rodrigues ${ }^{4}$
}

\begin{abstract}
Resumo: O presente artigo busca analisar a criminologia crítica e o sistema penal da atualidade. Para tanto, será comentado acerca da história da criminologia, sobre a Teoria do Etiquetamento Social e o sistema penal vigente no país. Ainda, será comentado acerca das funções das penas no sistema atual, não sendo esse o foco do presente escudo. Ao final, será demonstrado que o hodierno sistema penal tem se revelado seletivo e ineficaz em seus propósitos. Para alcançar o referido objetivo, serão utilizados estudos bibliográficos, sobretudo, de obras que versem sobre criminologia crítica e o sistema de justiça penal brasileiro
\end{abstract}

Palavras-chave: Direito Penal. Criminologia. Criminologia Crítica. Teoria do Etiquetamento Social.

\section{Brief notes on Critical Criminology and the Current Selective Criminal System}

\begin{abstract}
This article analyzes the critical criminology and the current criminal system. Therefore, it will be commented on the history of criminology, on the Labeling Theory and the current selective criminal system in the country. Still, it will be commented on the penalties functions in the current system, not being the focus of the present shield. Finally, it will be shown that today's criminal system has provec to be inefficient and selective in its purposes.In order to reach this goal, bibliographical studies will be used, especially, on critical criminology and the Brazilian criminal justice system.
\end{abstract}

Keywords: Criminal Law. Criminology. Critical Criminology. Labeling Theory

\section{Introdução}

A criminologia trata-se de ciência com caráter multidisciplinar, que tem escopo de estudar o crime e a pessoa que cometeu o delito, analisando, ainda a criminalidade, os processos de criminalização e as violências decorrentes da forma como se desenvolve o sistema penal.

\footnotetext{
${ }^{1}$ Graduação em direito pelo Centro Universitário SOCIESC - UNISOCIESC; Contato: josidenise1 @ gmail.com;

${ }^{2}$ Graduação em Direito pela Faculdade dos Guararapes, Jaboatão dos Guararapes - PE; Especialização em Direito Processual do Trabalho pela Faculdades Integradas de Cruzeiro, Brasil. Contato: athena.farias@ gmail.com;

${ }^{3}$ Graduação em Direito pela Universidade Federal Fluminense. Mestranda em Justiça Administrativa pela Universidade Federal Fluminense. Contato: gisannemarinho@gmail.com;;

${ }^{4}$ Mestranda em Educação pela Unissulivan Inc. Contato: laricesousa2008@ hotmail.com. 
Por sua vez, o surgimento da criminologia crítica traduz o momento em que criminologia tradicional não era mais suficiente para explicar e justificar a criminalidade, isto porque entender a criminalidade como patologias, indicando o tratamento ou eliminação daquele que cometesse um delito, não trazia a diminuição da criminalidade na sociedade.

Conforme será abordado, a Teoria do Etiquetamento Social teve grande influência nessa modificação da criminologia, pois promoveu um avanço ao ampliar o objeto de análise do crime e do sujeito criminoso, passando a averiguar a realidade além do cárcere.

Esta nova forma de estudo revelou que o aprisionamento não era utilizado apenas para fins de controlar a sociedade, mas também como meio de marginalização das classes mais desfavorecidas da população, o que é notório na hodierna sociedade brasileira.

Por fim, o estudo revela que o sistema penal brasileiro está pautado na seletividade, o que pode ser atestado por meio da análise do quantitativo e qualitativo dos condenados ao cárcere, o qual revela a predisposição a punição da parcela mais pobre da sociedade e a presença de patente tratamento desigual entre os indivíduos.

\section{Breve perspectiva histórica acerca da criminologia}

Surgiu no século XIX, como campo estudo, investigação e medicação do criminoso, por meio de uma metodologia positivista de experimentos e observação do homem. Seu nascimento e desenvolvimento inicial, deu-se, então, nos cárceres, em que o delito e a criminalidade são entendidos como realidades ontológicas; e o criminoso ocupa o lugar de sujeito anormal, que comete delitos em razão de problemas biológicos e/ou psíquicos que os acometem.

Esses estudos deram surgimento a criminologia racista, por meio da qual se afirmava que a tendência para a criminalidade era inerente aos genes dos indivíduos, proveniente de problemas físicos e mentais de natureza hereditária, conforme afirmou Henry Goddard, em 1913 (ZAFFARONI, 2012, p. 111). Ainda, em 1869, Francis Galton, em sua obra Hereditary Genius, defendeu que a raça branca era superior às demais, pois era capaz de reproduzir indivíduos com os genes mais perfeitos e superiores do mundo, momento em que ele criou a "eugenia", que se dispunha a estudar a herança biológica dos homens brancos.

Pode-se citar, ainda, as ideias de Madison Grant, que defendia a necessidade de se evitar a reprodução de criminosos, doentes, loucos e todos os indivíduos considerados de raças 
inferiores; e Lothrop Stoddard, que em sua obra The revolt agains civilization: the menace of the under man, apontava acerca dos perigos inerentes aos crescimentos do percentual de gentes de cor e sugeriu que a raça superior eliminasse as inferiores.

Para completar a esquizofrenia da época, em 1908, o Estado de Indiana sancionou a primeira lei de esterilização forçada ${ }^{4}$, que esterilizou diversos surdos, mudos, cegos, criminosos e enfermos mentais.

Segundo essa linha de pensamento, tem-se o surgimento do "darwinismo social", em 1859 e do "spencerianismo biológico", em 1876. Ambas as teses sustentavam a existência de uma predisposição genética e cromossômica, teoria perfeita para o governo totalitário da época, que utilizou isso como justificativa para eliminar boa parte das pessoas que eram consideradas prejudiciais à sociedade.

Enfim, percebeu-se que as consequências desse tipo de pensamento, estava causando um genocídio geral, o que ocasionou um desprestígio geral em relação a criminologia racista. Juntamente a isso, houve o forte movimento imigratório de países pobres para a Europa em decorrência da industrialização, que gerou a formação dos guetos (ANITUA, 2005, p. 247), momento em que surgiram as teorias da socialização e da estrutura social defeituosa ${ }^{5}$.

Após a segunda guerra mundial, houve uma verdadeira revolução nas teorias criminológicas, como revela a labeling approach theory ${ }^{6}$ (teoria do etiquetamento social), que era contrária a ideia de que a criminalidade estava correlacionada a uma ontologia-natural preexistente. Esta teoria deixa de focar no crime e no criminoso, e para a analisar o sistema criminal de justiça. Além disso, ela abandona o método etiológico para adotar um modelo típico do pluralismo axiológico, sendo este mais interativo.

Esta nova teoria inovou quanto aos efeitos produzidos pela etiqueta de criminoso, sendo esta a dimensão do sujeito; e em relação aos efeitos produzidos pelo desvio, impedindo que este

\footnotetext{
${ }^{4}$ A constitucionalidade dessa lei foi declarada pela Suprema Corte dos Estados Unidos da América e apenas declarada inconstitucional cinquenta anos depois.

${ }^{5}$ A principal diferença entre essas teorias é que a teoria da socialização não questiona fatores específicos do sistema social, político e econômico; já a teoria da estrutura social defeituosa não se importa com conhecimentos específicos sobre o autor do ceime.

${ }^{66}$ A teoria do labelling approach promoveu um importante avanço na ciência criminológica ao ampliar a análise do crime, e do sujeito tido como criminoso, para além das definições legais dos indivíduos efetivamente encarcerados. Com isso, a criminologia deixou de ser mera instituição do sistema para se tornar uma importante ferramenta de análise e compreensão do Direito Penal e suas instituições. (MUNIZ FILHO, OLIVEIRA, 2015 , p. 01)
} 
seja utilizado como justificativa para o controle de comportamentos e de pessoas, limitando, assim, as agências de controle e seus poderes de repressão.

\section{Da criminologia crítica e o sistema penal seletivo vigente}

A criminologia crítica trata-se de instituto que analisa o crime tomando por base as causas biológicas, psicológicas e ambientais que o levam indivíduo a cometê-lo. Sendo assim, conforme comenta Santos (2005, p. 1):

\footnotetext{
O estudo do objeto não emprega o método etiológico das determinações causais de objetos naturais empregado pela criminologia tradicional, mas um duplo método adaptado à natureza de objetos sociais: o método interacionista de construção social do crime e da criminalidade, responsável pela mudança de foco do indivíduo para o sistema de justiça criminal, e o método dialético que insere a construção social do crime e da criminalidade no contexto da contradição capital/trabalho assalariado, que define as instituições básicas das sociedades capitalistas.
}

Conforma já comentado, com a Teoria do Etiquetamento Social a criminologia alcançou um novo patamar, isto porque modificou a forma de definição de "criminoso", superando a antiga qualificação conferida pelas agências de controle social.

Agora o sujeito desviante que cometeu um delito, passa a ser analisado sob a ótica de um contexto de desigualdade ocasionado por um sistema capitalista, que causa a rotulação, bem como exclusão de indivíduos de forma que este fica mais vulnerável a ser condenado a sanções penais.

Com isso, tem-se um indivíduo que não é punido por suas ações, mas sim pelo que ele é taxado socialmente, ou melhor, com base em preconceitos existentes na sociedade em que está inserido. Isto ocorre principalmente porque o sistema penal e o arcabouço normativo é definido pela parcela da população que detém o poder e em prol dos interesses desse grupo.

Verifica-se a presença de um sistema penal, dotado de um conjunto de normas jurídicas dispõem sobre os crimes e suas respectivas penas, bem como disciplinam a validade dessas normas, a forma como se estrutura o crime, a aplicação das sanções e execução das penas impostas (BATISTA, 2004, p.27). 
Cabe mencionar que o sistema penal se diferencia do sistema de justiça, pois este último é mais amplo, sendo assim, o sistema penal pode ser visto como um fragmento do sistema de justiça.

Nesse diapasão, o sistema de justiça penal pode ser visto como aquele que engloba as normas referentes ao direito penal, ao direito processual penal, a organização judiciária, a execução penal, etc; sendo integrantes desse sistema a instituição policial, judiciária e penitenciária. Sobre o assunto, Vera Regina Pereira de Andrade (2006, p. 169) explica que:

\begin{abstract}
Por sistema penal entende-se, portanto, neste contexto, a totalidade das instituições que operacionalizam o controle penal (Parlamento, Polícia, Ministério Público, Justiça, Prisão) a totalidade das Leis, teorias e categorias cognitivas (direitos+ ciências e políticas criminais) que programam e legitimam, ideologicamente, a sua atuação e seus vínculos com a mecânica de controle social global (mídia, escola, universidade), na construção e reprodução da cultura e do senso comum punitivo que se enraíza , muito fortalecidamente, dentro de cada um de nós, na forma de microssistemas penais.
\end{abstract}

Por sua vez, Eugenio Zaffaroni (1995), conceitua o sistema de justiça criminal como forma de controle social punitivo e institucionalizado, que abarca o estudo do sistema de justiça e seus desdobramentos, por mais que estes sejam ilegais, como esquadrões da morte, tortura, etc. Com base nisso, percebe-se que o jurista defende a necessidade do estudo de um sistema de justiça mais realista, que engloba não apenas o conjunto normativo, como também o que ocorre na prática.

Logo, o sistema de justiça criminal vai além do estudo de um arcabouço legislativo, sendo imperioso a análise da realidade na qual ele encontra-se inserido. Nas palavras de Batista (2007 apud ZAFFARONI, 1984, p. 32):

Assim, o sistema penal é apresentado como igualitário, atingindo igualmente as pessoas em função de suas condutas, quando na verdade seu funcionamento é seletivo, atingindo apenas determinadas pessoas integrantes de determinados grupos sociais, a pretexto de suas condutas. As exceções, além de confirmarem a regra, são aparatosamente usadas para a reafirmação do caráter igualitário.

Esta seletividade aponta no sentindo da presença de um o sistema de justiça criminal incapaz de possibilitar a todos os meios de contraditório e a ampla defesa a integralidade da população, isto porque estamos diante de uma justiça penal classista e seletiva.

Nesse diapasão, podem-se elencar duas formas de criminalização: uma primária, que está diretamente ligada ao direito penal, sendo este reflexo de uma sociedade burguesa- 
individualista-patrimonialista; e uma secundária, relacionada com o caráter seletivo do sistema penal. Sendo assim, conforme ensina Baratta (2002, p. 176), é notório que:

[...] a seleção criminalizadora ocorre já mediante a diversa formulação técnica dos tipos penais e a espécie de conexão que eles determinam com o mecanismo das agravantes e atenuantes (é difícil como se sabe, que se realize um furto não "agravado).

Isso gera a punição dos indivíduos de classe-social mais desfavorecida de forma mais severa, enquanto que os crimes cometidos pela elite social são tratados de forma mais branda, em razão do nosso sistema valorizar o processo de acúmulo do capital. De acordo com Baratta (2002, p. 176):

\footnotetext{
"[...] os processos de criminalização secundária acentuam o caráter seletivo do sistema penal abstrato. Têm sido estudados os preconceitos e os estereótipos que guiam a ação tanto dos órgãos investigadores como dos órgãos judicantes"
}

É notório que a parcela social atingida pelo processo de criminalização é aquela mais desfavorecida, perceptível por meio de uma breve análise do contingente de pobres, analfabetos e semi-analfabetos, presentes em uma comunidade carcerária, que perfazem quase que a totalidade dos que estão ali inseridos.

Ademais, a população carcerária é julgada por juízes que, em sua maioria, são provenientes de classes sociais privilegiadas, o que aponta uma tendência a punir, isto porque é mais fácil causar dor a uma pessoa quando não a vemos ou ouvimos, bem como quando as ordens de punição são oriundas de uma "autoridade científica".

Isto exposto, é inegável a seletividade que acomete o sistema penal vigente, principalmente porque, de uma breve análise dos condenados, resta evidente que se pune três vezes mais os desviantes de classes sociais desfavorecidas, o que alerta a necessidade de remodelação do sistema.

\section{Das funções do sistema penal e da pena}

Dentre as funções do sistema penal, aponta-se duas como sendo as mais importantes, sendo uma aparente e uma real. 
A função aparente da pena envolve a falsa percepção de que ela é capaz de evitar que o indivíduo torne a cometer delito, pois, espera-se que o sujeito, após ser tirado do convívio social, tenha uma retribuição negativa pelo injusto cometido e retorne regenerado. Juarez Cirino dos Santos (2013, p. 2) comenta:

O discurso da prevenção especial como correção do criminoso pressupõe a capacidade da psicologia, da sociologia, da assistência social etc., de transformar a personalidade do preso mediante trabalhos técnico corretivos realizados no interior da prisão, segundo previsão legal: a pena deve ser aplicada conforme necessário e suficiente para prevenir o crime (CP, art. 59) e deve ser executada para permitir harmônica integração social do condenado (LEP, art. 1o ).

Nesse sentido, o que legitima a existência do sistema penal é a proteção dos bens jurídicos, o combate da criminalidade, bem como sua prevenção, a serem realizados por meio da imposição de penas que irão castigar e ressocializar os delinquentes, além de fornecer segurança jurídica aos acusados e segurança pública a sociedade.

Quanto a função real do sistema, esta traz a pena como algo repressivo e punitivo, aplicada, principalmente, sobre os desfavorecidos economicamente, o que alerta a existência de uma política criminal seletiva, classista e com traços racistas e xenófobos, que apenas tem por escopo legitimar a atuação punitiva estatal. Como resultado dessa política criminal existente no país, temos uma população carcerária composta, em sua maioria, por negros, pobres, analfabetos ou semi-analfabetos. Kilduff (2010, p. 247) faz os seguintes apontamentos sobre o assunto:

\begin{abstract}
Por detrás dessas soluções ilusórias que produzem mais mortes e destruição social, esconde-se a verdadeira essência do direito penal burguês, que, sobre a base de um corpo doutrinário de normas, legitima como necessária a intervenção de tipo repressiva sobre tudo aquilo considerado como uma ameaça e um estorvo ao modo de produção capitalista. Embora isto tenha uma continuidade histórica, a fase neoliberal do capitalismo revela a expansão do sistema penal como estratégia privilegiada de controle e gestão da pobreza, aprofundada principalmente por uma situação de desemprego maciço e estrutural.
\end{abstract}

É notório que o sistema penal vigente tem se revelado ineficaz, servindo apenas como escola do crime, o que agrava a questão da segurança no país. Ademais, há de se ressaltar a dificuldade que os ex-presidiários possuem de encontrar emprego, o que acaba por redirecionálos a marginalidade. 
Assim, tem-se um sistema penal aplicado de forma desigual e com intuito de obter o controle repressivo-punitivo da sociedade, o que revela semelhanças com o direito penal do inimigo, sendo este um verdadeiro direito de guerra.

\section{Considerações Finais}

Conforme restou demonstrado, a Teoria do Estiquetamento Social tornou possível a utilização da criminologia como ciência empírica e não como forma de sistema penal. Com isso, a criminologia crítica passou a ter como objetivo principal o de atuar como uma ação crítica-destrutiva do sistema penal desigual e opressor, com fulcro de transforma-lo em um sistema igualitário e libertário.

Como é sabido, o sistema penal brasileiro trata-se de sistema de controle social repressivo e preventivo, que aparentemente se faz necessário, pois justifica-se pelo discurso da proteção da sociedade, no entanto, tem revelado que sua função real é diferente da prometida, isto porque tem se apresentado como forma de legitimar o controle estatal sobre as classes mais vulneráveis, bem como para justificar situações de opressão e violência.

É perceptível que o Estado não tem obtido êxito na aplicação do sistema penal, pois, apesar da pena ser vista como algo a ser benéfico e necessário, a realidade do estrutura punitiva posta aponta no sentido de ser mero produtor de criminosos e reprodutor de desigualdades.

Com base nisso, a criminologia crítica, então, revela a necessidade de uma mudança radical no sistema seletivo de justiça penal brasileiro, que, no entanto, só será possível a partir de uma mudança no seio social, isto porque apenas é possível a modificação de um excluído após a modificação da sociedade excludente, visto que esta consiste na raiz dos mecanismos excludentes.

\section{Referências}

ANDRADE, Vera Regina Pereira de. Minimalismos, abolucionismos e eficienticismo: a crise do sistema penal entre a deslegitimação e a expansão. Revista Seqüência, n. 52, p. 163-182, jul. 2006.

Disponível

em: 
$<$ https://periodicos.ufsc.br/index.php/sequencia/article/viewFile/15205/13830>. Acesso em: 21/03/2018.

ANITUA, Gabriel Ignácio. Historias de los pensamentos criminológicos. Buenos Aires, Del Puerto, 2005.

BATISTA, Nilo. Introdução crítica ao direito penal brasileiro. $11^{\mathrm{a}}$ ed. Rio de Janeiro: Revan, 2007.

SANTOS, Juarez Cirino dos. Política Criminal: Realidades e Ilusões do Discurso Penal. Instituto de Criminologia e Política Criminal, 2013. Disponível em: < http://icpc.org.br/wpcontent/uploads/2013/01/realidades_ilusoes_discurso_penal.pdf $>$. Acesso em: 21/03/2018.

MUNIZ FILHO, José Carlos Cunha, OLIVEIRA, Larissa Teixeira. A formação do pensamento criminológico crítico materialista: da reação social à criminalização social. 2014. Disponível em: http://www.rbc.org.br/ojs/index.php/rbc/article/view/58. Acesso em: 20/03/2018.

ZAFFARONI, Engenio Raúl. La cuestión criminal. Buenos Aires, Planeta, 2012.

\section{Como citar este artigo (Formato ABNT):}

SANTOS, Josiéli Denise Brum dos; FARIAS, Athena de Albuquerque; MARINHO, Gisanne de Oliveira; RODRIGUES, Larice de Sousa. Breves apontamentos acerca da Criminologia Crítica e o Sistema Penal Seletivo Vigente. Id on Line Rev.Mult. Psic., 2018, vol.12, n.40, p.283-291. ISSN: 19811179.

Recebido: $17 / 03 / 2018$

Aceito 21/03/2018 